las piezas de Lope y Calderón traducidas al náhuatl por don Bartolomé Alva (cf. supra), hay un entremés, también en náhuatl, cuyos personajes son una vieja (ilamatzin), un muchacho (piltontli), un viejo, un alcalde, un escribano y dos sacristanes. El entremés tiene una trama muy simple, y termina en gritería y barahunda. Hunter cree que es obra original de Alva, y dice que el tema, "evidentemente mexicano" [?], recuerda los "juegos de escarnio de la Edad Media". [EI resumen que ofrece Hunter hace pensar en ciertos entremeses españoles de la época de Cervantes; no es difícil que se trate de una traducción más; en cuanto a los juegos de palabras que sólo tienen sentido en náhuatl, quizá se trate de simples adaptaciones de los que habría en el entremés original].

J. C. Davis, "Realism and humor in the Cid", pp. 66-73.-Comenta los pasajes del Poema del Cid en que hay pinturas realistas o rasgos humorísticos (como el episodio de Raquel e Vidas y el del león), y señala los recursos estilísticos de que se vale el poeta allí y en muchos otros lugares: naturalidad del diálogo, frecuencia de detalles descriptivos, precisión geográfica, exactitud de las cifras, caracterización física y psicológica de los personajes, etc.

C. W. Steele, "The Krausist educator as depicted by Galdós", pp. 136-142.Los ideales humanitarios y reformistas de León Roch (La familia de León Roch, 1878) y de Máximo Manso (El amigo Manso, 1882) reflejan con bastante fidelidad los de los krausistas españoles (con cuyo jefe espiritual, Giner de los Ríos, mantuvo Galdós estrecha amistad). Los dos personajes fracasan en su empeño, lo cual significa, seguramente, que el novelista no creía que España fuera terreno abonado para el programa pedagógico del krausismo. Roch y Manso "son dos de los personajes más simpáticos de Galdós, y a la vez dos de sus idealistas más patéticos”.

M. V. CAMpbell, "The cuentos of Oscar Castro Zagal", pp. 167-176.-Breve biografía de este poeta y cuentista chileno (1910-1947) y valoración de sus tres volúmenes de cuentos. Los mejores, en opinión de la profesora Campbell, son los del primer libro, Huellas en la tierra (1940). Los más tardíos están demasiado recargados de símiles y suelen ser melodramáticos o de mal gusto.-M. A. V.

\title{
ANUARIO MUSICAL
}

Tomo 1 (1946).

H. Spanke, "La teoría árabe sobre el origen de la lírica románica a la luz de las últimas investigaciones", pp. 5-18.-Rebate dicha teoría desde varios ángulos. "En lo concerniente a la forma musical general, la canción latina y la canción romance de la Edad Media forman un todo trabado, sin influencias extrañas". "La semejanza... entre el zéjel y el virelai aparece como producto externo y casual de dos líneas evolutivas independientes". Las coincidencias temáticas entre la lírica provenzal y la árabe pueden explicarse por cierta semejanza de las condiciones sociales y sobre todo por la igualdad básica del alma humana, que "en diferentes puntos del espacio y del tiempo lleva forzosamente a fenómenos paralelos". Por lo demás, la influencia árabe no es probable ni geográfica ni históricamente.

F. Pujol, "Clasificación de las canciones populares. Metodología", pp. 19-29.Propone una "clasificación de archivo" para la eventual formación de un Cancionero nacional español. Ve la necesidad de prescindir de la música y basarse fundamentalmente en los temas poéticos, como se ha venido haciendo; a la vez cree inevitable ciertas arbitrariedades, como la de atender en determinados casos al género poético o musical de la canción y no a su asunto. 
Tomo 2 (1947).

M. Querol, "La música de los romances y canciones mencionados por Cervantes en sus obras", pp. 53-68.-Reproduce la melodía de varios de esos romances y cantares, según aparece en obras polifónicas y vihuelísticas del siglo xvi [que no es siempre, desde luego, la que conocería Cervantes]. Además hace referencia a otras melodías que no publica. [La de "Cata el lobo do va" puede ahora verse en la ensalada "La justa" de Mateo Flecha, ed. H. Anglés, p. 48].

\section{Tomo 3 (1948).}

M. Schneider, "Tipología musical y literaria de la canción de cuna en España", pp. 3-58.-En las pp. 13-19 examina los temas literarios y da a algunos de ellos una interpretación simbólica; por ejemplo, el coco, la loba, la reina mora o el tio con que se amenaza a los niños es la "Magna Mater o uno de sus animales de la noche negra (Capricornio-Piscis)".

H. ANGLÉs, "El archivo musical de la catedral de Valladolid", pp. 59-108.Varios manuscritos que describe contienen canciones profanas o religiosas en español, de los siglos xvi a xvirr.

J. Subirá, “Jaime Facco y su obra musical en Madrid”, pp. 109-132.-Noticia sobre una ópera desconocida con música del compositor italiano y letra de Joseph Cañizares: Amor es todo invención, Júpiter y Amphitrión, representada en 1720.

J. Romev, "El canto dialogado en la canción popular. Los cantares a desafío", pp. 133-161.-Después de hablar del diálogo en canciones de navidad, de boda y de danza, examina más en detalle los cantares de desafío, o sea de competencia poético-musical. Cita testimonios de Italia, Francia y Cataluña, de Galicia y Asturias ("donde se ha conservado mejor el canto amebeo popular") y de otras regiones de la Península. [No hace suficiente justicia a América]. Finalmente relaciona esos cantares con varios géneros medievales, como la pastorela y el débat, a los cuales atribuye un origen popular.

\section{Tomo 4 (1949).}

M. Schneider, "Los cantos de lluvia en España. Estudio etnológico comparativo sobre la ideología de los ritos de pluviomagia", pp. 3-55.-Relaciona varios cantares, cuentos y costumbres de España (no necesariamente referentes a la lluvia) con antiguas creencias -sobre todo brahmánicas- en torno al nacimiento de la lluvia. [La supervivencia de símbolos parece evidente en muchos casos, no en todos]. Al final explica el simbolismo mítico del romance del "Conde Olinos".

J. Romeu Figueras, "La poesía popular en los cancioneros musicales españoles de los siglos xv y xvı”, pp. 57-91.-Publicación comentada de 65 textos (y de otros muchos en las notas), ordenados por su tema. [No pueden considerarse como serranillas todos los que se refieren a la sierra o a la serrana ( $\mathrm{pp}$. 77-78, nota), ni como canciones de "monja contra su gusto" las dos primeras de las pp. 79-8o, nota 1]. Establece una discutible división teórica -que luego aplica con muchas vacilaciones- entre dos tipos: $I$ ) canciones estrictamente populares, o sea creadas por uno o "varios poetas anónimos pertenecientes al estamento del pueblo sencillo" (p. 59; aunque, p. 89: "no sólo concurre el estamento más sencillo, sino también los poetas que... se adaptan a la mentalidad" del pueblo), y 2) canciones anónimo-tradicionales, "poesía que pudo o no haber subido de la villa a la corte y descender del salón a la cabaña" (p. 6o; aunque después ya sólo aplica el término a la poesía de origen culto). Entre los textos interesan 
sobre todo los tomados de fuentes inéditas, como el del Cancionero de la Colombina. [Aunque no siempre están transcritos con fidelidad: el núm. xLIII, por ejemplo, debe ser "Querer vieja yo... porque la quisiese yo. / Querer vieja..."]. Muy acertada la observación sobre el "nuevo tipo de cancionística" que surge a principios del siglo xvir y "que se acerca mucho a la actual poesía popular".

A. DE LARreA, "La saeta", pp. 105-135--Trata brevemente sobre las formas métricas y musicales y los temas de las antiguas saetas de 4,5 ó 6 octosílabos (las saetas aflamencadas "por seguiriyas" son una "falsificación burdísima"), y con más extensión sobre su origen; se inclina, sin mucha convicción, por la hipótesis que le ha suministrado M. Schneider: la saeta es "supervivencia de un rito remoto de fecundidad..."

J. Subirá, "Un manuscrito musical de principios del siglo xvirr. Contribución a la música teatral española", pp. 181-191.-El ms. contiene piezas polifónicas hechas sobre parlamentos dramáticos de varios autores del siglo xvir, principalmente de Calderón, y sobre algunas poesías líricas.

\section{Tomo 5 (1950).}

J. Romeu Figueras, "El cosante en la lírica de los cancioneros musicales españoles de los siglos xv y xvr”, pp. 15-61.-Con la idea de que la canción paralelística y encadenada es no sólo típica, sino exclusiva de la lírica gallegoportuguesa [cf. la acertada réplica de E. Asensio en su libro Poética y realidad en el cancionero peninsular de la Edad Media, pp. 196-204], supone que de ésta derivan todos los cantares castellanos que adoptan tal esquema y aun otros de distinta estructura o compuestos de una sola estrofa, los cuales, dice, son "cosantes" deteriorados o mutilados por ignorancia de los recopiladores [sobre el erróneo uso tradicional de cosante, cf. Asensio, op. cit., pp. 186-191]. A pesar de que considera el esquema clásico de la cantiga d'amigo como elaboración culta de la técnica paralelística popular, trata de reconstruir según ese mismo esquema ocho cantares populares “deteriorados". En seguida publica 56 cantares muy breves, cuyo carácter de "cosantes fragmentarios" intenta demostrar en la última parte del artículo. [Ampliando el campo de observación se debilita la idea del origen gallego y paralelístico-encadenado de muchos de los textos citados; se ve también la frecuencia de glosas en tercetos monorrimos, que Romeu diluye en una pareja de dísticos encadenados].

J. Subirá (ed.), "Libro de danzar de don Baltasar de Rojas Pantoja, compuesto por el maestro Juan Antonio Jaque (s. xvir)", pp. 19o-198.-La obra (publicada a base de dos copias manuscritas tardías) tiene interés, entre otras cosas, para la historia del teatro. Describe minuciosamente los pasos de la pavana, la gallarda, el villano, etc.

Tomos 6 (1951) y 7 (1952): no contienen artículos de interés histórico-literario.

Tomo 8 (1953).

M. Schneider, “¿Existen elementos de música popular en el Cancionero musical de Palacio?", pp. 177-192.-Muchas de sus composiciones parecen haberse basado en melodías populares, a juzgar por las semejanzas (nunca coincidencias totales) que con ellas presentan ciertos cantares actuales (da 19 ejemplos de correspondencias melódicas o rítmicas).-M. F. A. 